\title{
Activity levels and predator detection by amphipods infected with an acanthocephalan parasite, Pomphorhynchus laevis
}

\author{
Bahram S. Dezfuli ${ }^{1}$, Barbara J. Maynard ${ }^{2}$ and Todd A. Wellnitz ${ }^{2}$ \\ ${ }^{1}$ Dipartimento di Biologia, Università di Ferrara, Via L. Borsari 46, Ferrara 44100, Italy; \\ ${ }^{2}$ Department of Biology, Colorado State University, Fort Collins, CO 80523, USA
}

Key words: Acanthocephala, Pomphorhynchus laevis, parasitized crustacean, Echinogammarus stammeri, alteration of host activity

\begin{abstract}
The acanthocephalan parasite Pomphorhynchus laevis (Müller, 1776) uses freshwater amphipods as its intermediate host. In order to complete the life cycle, the infected amphipod must be consumed by a fish, where the acanthocephalan will mature and reproduce. Parasite transmission, and therefore fitness, could be enhanced if infected amphipods fail to detect or avoid predatory fish. We compared the activity levels of infected and non-infected amphipods, Echinogammarus stammeri (Karaman, 1931), in both the presence and absence of odours from its natural, definitive host, the fish Leuciscus cephalus (L.). Throughout the experiment, infected amphipods were more active than were non-infected individuals. The non-infected amphipods reduced their activity after the addition of fish odours, but the infected amphipods failed to show a significant decrease. The failure of infected amphipods to reduce activity levels in the presence of fish odour may reflect a parasite strategy to increase its chances of transmission by making its amphipod host more vulnerable to predation by fish.
\end{abstract}

Behavioural avoidance of predators is an important survival strategy for many animals. In the case of animals infected with parasites, however, the behavioural phenotype of the host animal may be the result of two competing genotypes: that of the host, which benefits from avoiding predators in order to survive and reproduce; and that of the parasite, which benefits from being eaten by the host-predator, where it will mature and reproduce (Moore and Gotelli 1990). There are examples of parasites that change their host's behaviour in ways consistent with increased predation (Bethel and Holmes 1973, Moore 1983, Lafferty and Morris 1996, Bakker et al. 1997).

One common response to infection is hyperactivity (Poulin et al. 1992, Urdal et al. 1995, Wedekind and Milinski 1996). Over-active individuals are likely to be more visible and exposed to predators, so this could be a strategy on the part of the parasite to increase its transmission. On the other hand, increased activity could also reflect the host's attempts to meet the greater nutritional demands imposed by infection (Jakobsen and Wedekind 1998). One potential clue to determining whether an altered behaviour is a parasite or a host strategy is whether the behaviour persists in the presence of predators. If the intermediate host diminishes its activity in the presence of predators, then this would challenge the idea that the hyperactivity was a parasite strategy, because the altered behaviour is not performed when it would benefit the parasite most. However, if the host remains hyperactive in the presence of a predator, then this would suggest that the hyperactivity is either the result of behavioural manipulation by the parasite, or a host strategy and the benefits of hyperactivity outweigh the risks of predation. Increased hyperactivity in the presence of a predator would suggest even more strongly that the behaviour change is a parasite, rather than a host, strategy.

This study examines the behaviour of amphipods infected with an acanthocephalan parasite in the absence and presence of chemical cues -here referred to as "odours"- from fish, a major predator of amphipods and definitive host of the parasite. Freshwater amphipods have been shown to decrease their activity in the presence of fish (Andersson et al. 1986, Wooster 1998), and fish odours are sufficient to invoke reduced activity levels in laboratory and field studies (Williams and Moore 1985, Holomuzki and Hoyle 1990). We asked whether parasitic infection influences this predator avoidance behaviour.

In the River Brenta of northern Italy, the helminth Pomphorhynchus laevis (Müller, 1776) uses the amphipod Echinogammarus stammeri (Karaman, 1931) as its intermediate host, where the worm undergoes its larval development. Once the worm has reached a resting stage known as a cystacanth, it is then infective to its next host, fish of several species (Hine and Kennedy 1974), but in our system primarily the chub, Leuciscus cephalus (L.). Once a fish eats an infected amphipod, the cystacanth is released into the intestine, where it attaches, matures, and reproduces. The mature parasite's fertilized eggs eventually pass out of the digestive tract to be eaten by amphipods, thus beginning the life cycle anew.

Previous studies have shown that $P$. laevis induces behavioural alterations in both E. stammeri (Maynard et 
al. 1998) and in Gammarus pulex, an amphipod host common in other parts of Europe (Kennedy et al. 1978, McCahon et al. 1991). In both host species, parasitized amphipods display increased drift behaviour, altered responses to light, and increased activity levels. These drift studies were conducted in rivers with fish, indicating that increased drifting persists in the presence of predators, but predator presence was not measured or controlled (McCahon et al. 1991, Maynard et al. 1998). The present study was conducted in artificial stream channels where exposure to chemical cues from fish could be manipulated experimentally and the behaviour of individual amphipods compared before and after such exposure.

This study was designed to assess whether infected $E$. stammeri are more active than non-infected amphipods, whether non-infected E. stammeri decrease their activity level in response to chemical stimuli from predatory fish, and whether E. stammeri infected with $P$. laevis respond in a similar manner.

\section{MATERIALS AND METHODS}

Study organisms. Amphipods were collected from the River Brenta on 8 March 1997, and transported in aerated stream water to Duebendorf, Switzerland, where they were maintained in artificial stream channels (see below) and fed algae and aquatic vegetation collected locally.

Chub (Leuciscus cephalus L.) were collected from the River Toess, Switzerland, on 13 March 1997, by electroshocking. Throughout the experiment the fish were held in 22litre tanks of aerated, non-chlorinated tap water and fed stream invertebrates (primarily mayflies) collected locally. Stream vegetation and terracotta potsherds provided refuges. Fresh water continuously flowed through tanks at a rate of approximately $2 \mathrm{l} / \mathrm{min}$. Seven chub of $15-20 \mathrm{~cm}$ length were held in a 22-litre holding tank until the beginning of the fish treatment. At that time, four chub were moved to the 22-litre exposure tank, and maintained as before. All fish were released at the end of the experiment.
Artificial stream design and operation. The channel design has been described previously (Wellnitz and Ward 1998). Sixteen artificial streams were constructed of Plexiglas ${ }^{\text {TM }}$. Each circular channel was $17 \mathrm{~cm}$ in diameter, 8 $\mathrm{cm}$ deep, and had a $4 \times 9 \mathrm{~cm}$ (diameter $\times$ height) standpipe mounted at the centre (Fig. 1). Water entered the streams through submerged nozzles that were angled sideways to provide current, and exited through drainage holes cut into the standpipes. The drainage holes maintained a water depth of $5.5 \mathrm{~cm}$ and were covered with screen collars $(1 \mathrm{~mm}$ mesh) to prevent amphipods from being washed out of the channels. Water exchange rates in channels were $11.2 \pm 0.44 \mathrm{ml} / \mathrm{s}$ (mean $\pm \mathrm{SE} ; \mathrm{n}=16$ ).

Non-chlorinated spring water was fed to the channels through a PVC pipe fitted with spigots along its length. Tygon $^{\text {TM }}$ tubing connected individual spigots to the 16 channels; current velocity within each stream channel was controlled by adjusting the spigots. Channel current was kept at approximately $1.3 \pm 0.1 \mathrm{~cm} / \mathrm{s}($ mean $\pm \mathrm{SE} ; \mathrm{n}=16)$, a speed which allowed the amphipods to swim and drift normally. Approximately one-fifth of the bottom of each channel was covered with a single layer of gravel $(8-16 \mathrm{~mm}$ diameter particles) to provide refuges for amphipods.

Water from the fish exposure tank was siphoned into each channel throughout the experiment. The rate of flow from the tank to each channel was $2.8 \pm 0.1 \mathrm{ml} / \mathrm{s}($ mean $\pm \mathrm{SE})$.

The experiment was conducted in a greenhouse illuminated by natural lighting. Water temperature, measured with a calibrated thermistor, showed diurnal fluctuations between 8.5 and $10.5^{\circ} \mathrm{C}$. Light levels, measured with a Licor ${ }^{\mathrm{TM}}$ spherical quantum PAR sensor, oscillated between $1000 \mu \mathrm{mol} / \mathrm{m}^{2} / \mathrm{s}$ during the day and $0.001 \mu \mathrm{mol} / \mathrm{m}^{2} / \mathrm{s}$ at night.

Experimental procedure. Three amphipods were placed into each of 16 channels on 21 March 1997 (day 0). All three amphipods in each channel were either infected with one cystacanth or non-infected, as determined by observing the parasites through the amphipods' exoskeletons (previous work had found this technique to be reliable and accurate; Maynard, pers. obs.). Field and preliminary observations in the channels

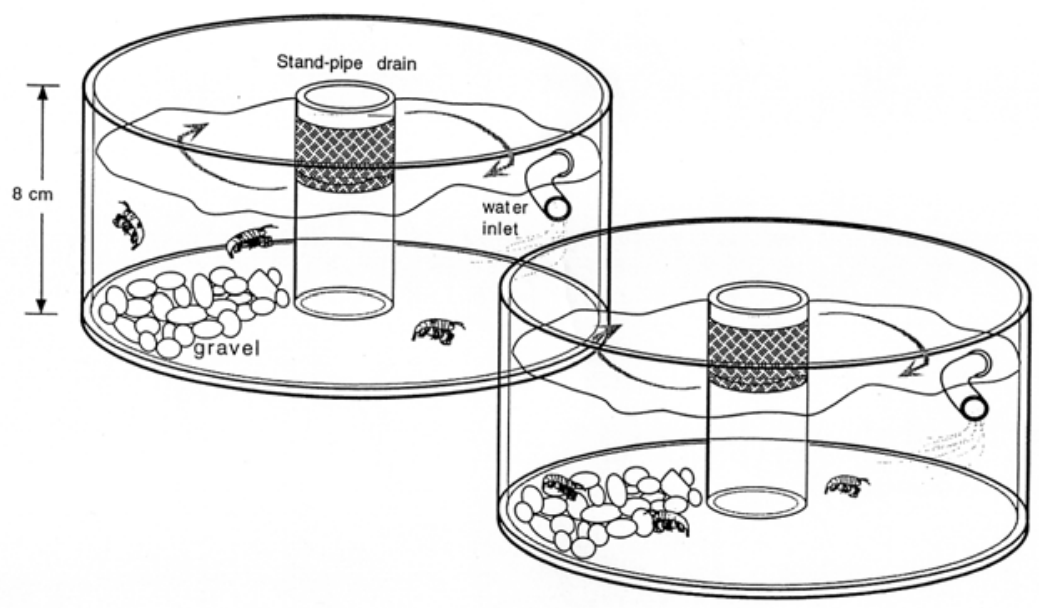

Fig. 1. Artificial stream channels. Freshwater came in through the water inlet and drained through the mesh standpipe collar; water from the fish exposure tank entered through a separate tube (not shown). 
indicated that amphipods are inactive during the majority of daylight hours, with activity increasing in the evening. Light was too dim for observations after 22:00, therefore observations were conducted from 19:00 to 21:30. Observations were conducted each evening on days 1 through 4 , and again on days 6 through 8 , allowing the amphipods a full day to acclimatize to the channels before the beginning of the experiment. Each half hour from 19:00 to 21:30, each channel was observed for $1 \mathrm{~min}$, yielding $6 \mathrm{~min}$ of observations per channel per evening. During each observation, the number of complete up- and downstream laps by any amphipod in each channel was counted. As used here, a "lap" constitutes a complete circumnavigation of the channel's raceway by an amphipod. Only laps were counted, whereas other signs of hyperactivity (e.g., sideways or back-and-forth movements) were not quantified. Once each morning between 09:00 and 09:40, all channels were scanned to see how many amphipods were active in each channel during the daylight. Throughout the experiment, amphipods in the channels were fed a clump of green algae in the morning that was removed in the afternoon.

On day 5 at 18:35, 4 chub were introduced into the fish exposure tank, thus beginning the fish treatment for each channel. This tank contained stream vegetation, stream invertebrates, and terracotta potsherds throughout the experiment; thus, the only change in the exposure tank at the beginning of the fish treatment was the addition of the fish.

Analysis. The total number of complete up- and downstream laps in each channel was summed over observation times and days for each fish treatment. Upstream and downstream laps were summed separately. The effects of infection and fish stimuli on the number of up- or downstream laps made were assessed with a 2-factor, repeated measures analysis of variance, using the MANCOVA module of Statistica $^{\mathrm{TM}}$. Tukey's Honest Significant Different (HSD) was used for multiple comparisons within treatments. Lap sums were square-root transformed in order to meet the assumption of homogeneity of variance, as determined by the Cochran $\mathrm{C}$ test. For all statistical tests, a probability of less than 0.05 was required to find a significant difference.

To examine more closely the effect of fish odour, we computed each channel's mean daily number of up- or downstream laps prior to fish treatment. For each day after fish treatment, a paired $t$-test was used to compare the number of laps on that day to the mean daily number of laps prior to fish treatment. These paired $t$-tests were calculated separately for channels containing parasitized and non-parasitized amphipods and for up- and downstream laps. Also, to compare parasitized and non-parasitized amphipods, the total number of up- or downstream laps on each day for each channel was standardized by dividing by that channel's mean daily number of up- or downstream laps prior to fish treatment. Each day's standardized lap scores for channels with parasitized versus non-parasitized amphipods were compared to each other using a two-sample $t$-test.

Morning activity levels of infected and non-infected amphipods were compared using the Mann-Whitney U test. A non-parametric test was used because the data were not normally distributed.

\section{RESULTS}

Amphipod mortality for both infected and noninfected amphipods was very low. Over the course of the experiment with 48 amphipods, 1 non-infected and 2 infected amphipods died, one each on the fifth, seventh, and eighth days of observations. To account for the losses, the number of laps made in any channel in which an amphipod had died was multiplied by $3 / 2$. One precopula pair formed in each of five channels containing non-infected amphipods. Any lap made by a precopula pair was counted as two laps, one for each of the two in the pair.

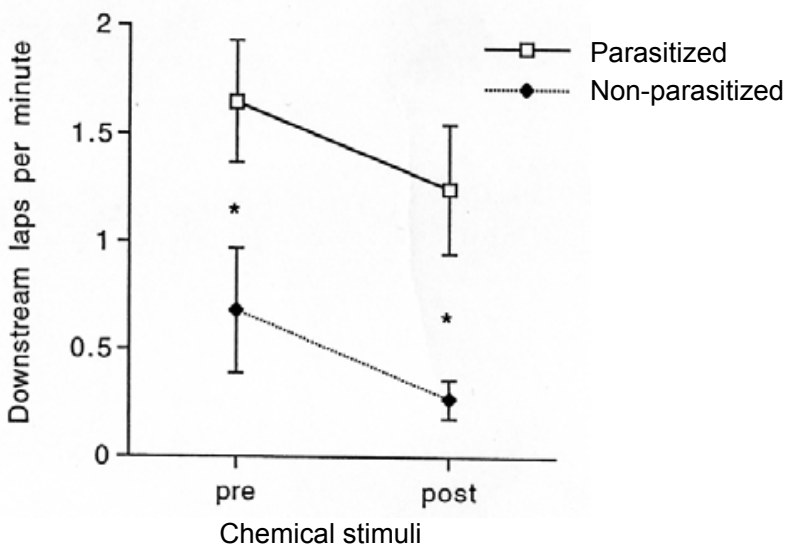

Fig. 2. The mean number of downstream laps per minute of observation in the absence (pre) or presence (post) of fish chemical stimuli. Error bars represent \pm 1 standard error. Asterisks indicate significant differences $(p<0.05)$ between parasitized and non-parasitized amphipods.

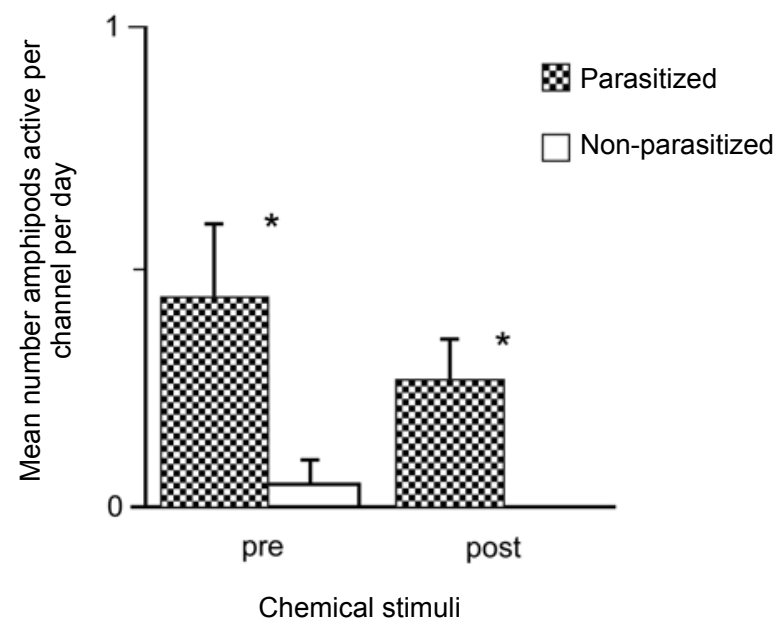

Fig. 3. The mean number of amphipods active per channel per day during morning observations in the absence (pre) or presence (post) of fish chemical stimuli. Error bars represent \pm 1 standard error. Asterisks indicate significant differences $\mathrm{p}<0.05$ ) between parasitized and non-parasitized amphipods. 


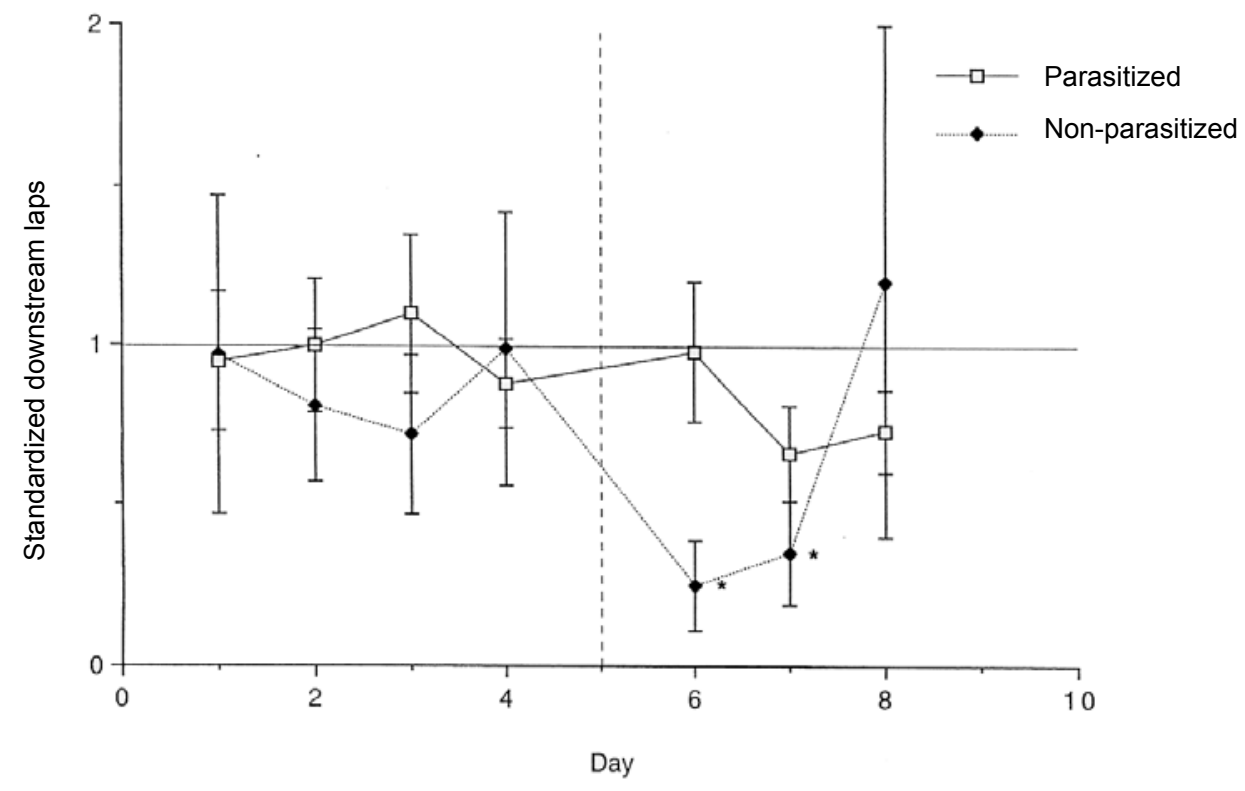

Fig. 4. Downstream laps, standardized as described in the text. Error bars represent \pm 1 standard error.

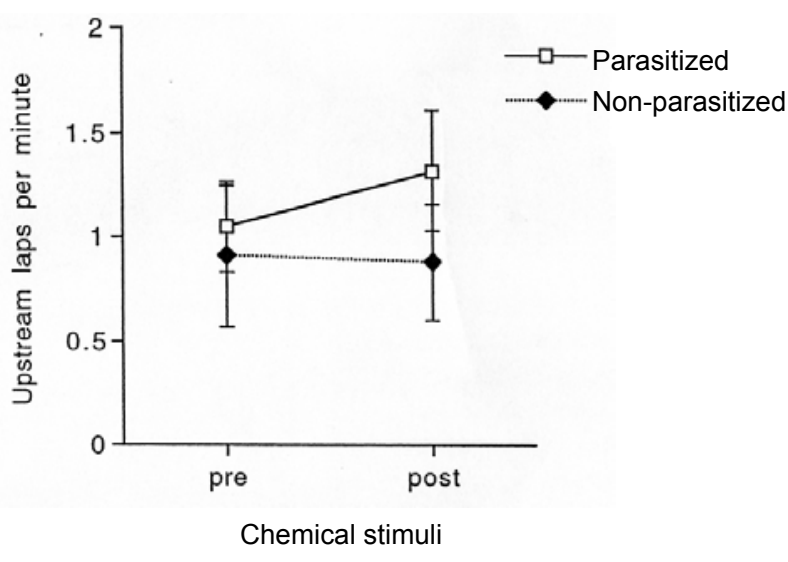

Fig. 5. The mean number of upstream laps per minute of observation in the absence (pre) or presence (post) of fish chemical stimuli. Error bars represent \pm 1 standard error.

Throughout the study, parasitized amphipods seemed to be hyperactive. Infected amphipods made more downstream laps than did non-infected amphipods (Fig. 2; MANOVA, df $=1,14 ; \mathrm{F}=11.5, \mathrm{p}=0.004)$; this pattern held both before (Fig. 2; Tukey HSD, $p=0.002$ ) and after $(p=0.004)$ the addition of chemical stimuli. During the daytime observations, the parasitized amphipods were more active both before (Fig. 3; MannWhitney $\mathrm{U}, \mathrm{T}=13.2, \mathrm{n}=8,8, \mathrm{p}<0.05$ ) and after (Fig. 3; Mann-Whitney $\mathrm{U}, \mathrm{T}=0.67, \mathrm{n}=8,8, \mathrm{p}<0.05)$ the addition of fish stimuli.

The addition of fish chemicals also had significant effects on activity. Taken together, the two groups of amphipods made fewer downstream laps after the fish tank water was added to the channels (Fig. 2;
MANOVA, $\mathrm{df}=1,14 ; \mathrm{F}=11.8, \mathrm{p}=0.004)$. Considered separately, neither parasitized (Fig. 2; Tukey HSD; $p=$ 0.08 ) nor non-parasitized (Fig. 2; Tukey HSD; $p=0.16$ ) amphipods made significantly fewer downstream laps after the addition of fish odours. There was no significant interaction between fish treatment and infection (Fig. 2; MANOVA, $\mathrm{df}=1,14 ; \mathrm{F}=0.08, \mathrm{p}=$ 0.8 ). However, looking at responses over days shows a different pattern. The greatest change in response to fish odours was downstream laps by non-parasitized amphipods one (Fig. 4; paired $t$-test, $\mathrm{n}=8, \mathrm{~T}=-5.22, \mathrm{p}$ $=0.0013$ ) and two days (paired $t$-test, $\mathrm{n}=8, \mathrm{~T}=-4.0, \mathrm{p}$ $=0.0053$ ) after addition of fish odours. The parasitized amphipods did not show a significant drop in the number of downstream laps on any day after the addition of fish odours, and the non-parasitized amphipods were not significantly different from their pre-fish odour scores on day 8 . The between groups difference in standardized scores for parasitized versus nonparasitized amphipods was significant only on day 6 (two-sample $t$-test, $\mathrm{n}=8,8, \mathrm{~T}=2.76, \mathrm{p}=0.017$ ).

The overall number of upstream laps was not different for infected versus non-infected amphipods (Fig. 5; MANOVA, $\mathrm{df}=1,14 ; \mathrm{F}=1.0, \mathrm{p}=0.33$ ), nor did the two groups change their upstream activity in the presence of fish stimuli (Fig. 5; MANOVA, df = 1, 14; $\mathrm{F}=1.1, \mathrm{p}=0.32$ ). There was no significant interaction between fish treatment and infection (Fig. 5; MANOVA, $\mathrm{df}=1,14 ; \mathrm{F}=0.50, \mathrm{p}=0.49)$. Looking at responses over days, only the difference between infected and non-infected amphipods on day 7 was significant (Fig. 6; two-sample $t$-test, $\mathrm{n}=8,8, \mathrm{~T}=2.35$, $\mathrm{p}=0.034$ ). The parasitized amphipods made more laps on day 7 than they did on average before the addition of fish stimuli, but this difference was not significant. 


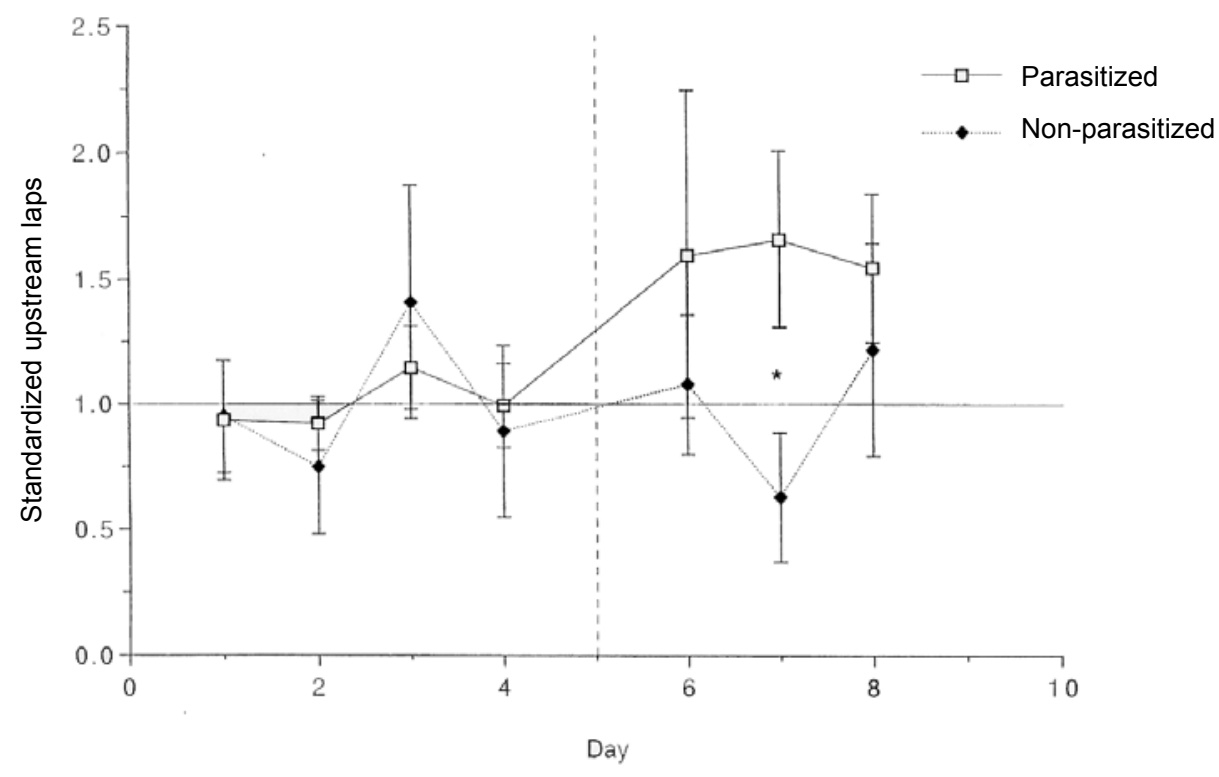

Fig. 6. Upstream laps, standardized as described in the text. Error bars represent \pm 1 standard error. The asterisk between bars indicates a significant difference $(\mathrm{p}<0.05)$ between the parasitized and non-parasitized amphipods.

\section{DISCUSSION}

Infected amphipods were more active than noninfected individuals, regardless of whether or not fish odours were present. These findings are consistent with a previous drift study in the River Brenta: infected amphipods were much more likely to be caught in drift nets throughout the day than were non-infected individuals (Maynard et al. 1998). This hyperactivity, present during the day as well as during the more active evening hours, could make the infected individuals more susceptible to predation by fish.

Non-infected amphipods decreased their activity after the addition of fish odours, as previously reported (Williams and Moore 1985, Holomuzki and Hoyle 1990). Infected amphipods, however, did not. Whether the amphipods were unable to detect the fish odours, or whether they detected them but did not respond accordingly, remains to be determined. Regardless, the persistence of hyperactivity by infected amphipods in the presence of fish odours leaves open the possibility that this behaviour is a parasite strategy.

It could be argued that the decreased downstream activity by non-infected amphipods in the presence of fish stimuli was due to an order effect, rather than to the fish treatment. Because we had no effective means to wash the fish stimuli from the Plexiglas ${ }^{\mathrm{TM}}$ channels, the fish treatment was applied to all channels only once, after the behaviour in the absence of fish stimuli had been observed. However, several species of freshwater amphipods are known to decrease their activity in response to chemical cues from fish (Williams and Moore 1985, Holomuzki and Hoyle 1990). In addition, the non-parasitized amphipods showed a sharp decrease in downstream activity on the observation day immediately following the addition of fish odours, followed by a return to pre-fish levels after 3 days of exposure, a pattern we would not expect if the decreased activity was due to extended time in the channels. Finally, amphipods either maintained or increased their number of upstream laps after the addition of fish odour. Since swimming upstream would presumably be more energetically expensive than downstream, we would not expect this pattern if the amphipods were stressed from being in the channels.

Parasitized and non-parasitized amphipods showed different up- versus downstream responses. In flowthrough systems, amphipods have been shown to detect downstream fish odours and drift accordingly (Dahl et al. 1998). However, with our circular channels, it is difficult to determine whether the cues would have been interpreted as coming from up- or downstream, or both, which makes it difficult to interpret the disparity in upversus downstream responses by the two groups of amphipods.

The hyperactivity of parasitized amphipods throughout the study could be a host strategy, for example to find more or more varied food, or it could be a parasite strategy to increase the likelihood of transmission. A significant change in this activity in the presence of fish odours could have given us a strong indication as to whether it is a parasite or a host strategy. An increase would have indicated that hyperactivity (Poulin et al. 1992, Pulkkinen et al. 2000) is a parasite manipulation of host behaviour, since it is difficult to imagine how becoming even more active while predators are present would benefit the amphipod. A decrease would have provided strong support for the idea that hyperactivity is 
a host strategy, because the behaviour change would have failed to persist when it would benefit the parasite most. The absence of any such significant response to fish odours makes it difficult to label the hyperactivity exhibited by infected amphipods as a host or a parasite strategy.

Predation-risky behaviours that may be host strategies are not unknown. Jakobsen and Wedekind (1998) found that copepods infected with a cestode were less risk sensitive than were non-infected conspecifics. While Jakobsen and Wedekind (1998) do not dismiss the possibility of manipulation by the parasite, they consider it more likely that this is a host strategy to decrease competition for food that inadvertently increases the parasite's chances for transmission.

Regardless of whether or not the increased activity of infected amphipods is a result of active manipulation by the parasites, it most likely results in increased parasite fitness through increased transmission.

Acknowledgements. J.V. Ward and Andreas Frutiger of the Swiss Federal Institute for Environmental Science and Technology provided laboratory facilities and space. B.J.M. was supported by a grant from the Whitehall Foundation to William G. Wright.

\section{REFERENCES}

ANDERSSON K.G., BRÖNMARK C., HERRMANN J., MALMQVIST B., OTTO C., SJÖRSTRÖM P. 1986: Presence of sculpins (Cottus gobio) reduces drift and activity of Gammarus pulex (Amphipoda). Hydrobiologia 133: 209-215.

BAKKER T.C.M., MAZZI D., ZALA S. 1997: Parasiteinduced changes in behavior and color make Gammarus pulex more prone to fish predation. Ecology 78: 10981104.

BETHEL W.M., HOLMES J.C. 1973: Altered evasive behavior and responses to light in amphipods harboring acanthocephalan cystacanths. J. Parasitol. 59: 945-956.

DAHL J., NILSSON P.A., PETTERSSON L.B. 1998: Against the flow: chemical detection of downstream predators in running waters. Proc. R. Soc. Lond. (B) 265: 1339-1344.

HINE P.M., KENNEDY C.R. 1974: Observations of the distribution, specificity, and pathogenicity of the acanthocephalan Pomphorhynchus laevis (Müller). J. Fish Biol. 6: 521-535.

HOLOMUZKI J.R., HOYLE J.D. 1990: Effect of predatory fish presence on habitat use and diel movement of the stream amphipod, Gammarus minus. Freshwater Biol. 24: 509-517.

JAKOBSEN P.J., WEDEKIND C. 1998: Copepod reaction to odor stimuli influenced by cestode infection. Behav. Ecol. 9: 414-418.

KENNEDY C.R., BROUGHTON P.F., HINE P.M. 1978: The status of brown and rainbow trout, Salmo trutta and $S$. gairdneri as hosts of the acanthocephalan, Pomphorhynchus laevis. J. Fish Biol. 13: 265-275.

LAFFERTY K.D., MORRIS A.K. 1996: Altered behavior of parasitized killifish increases susceptibility to predation by bird final hosts. Ecology 77: 1390-1397.

MAYNARD B.J., WELLNITZ T.A, ZANINI N., WRIGHT W.G., DEZFULI B.S. 1998: Parasite-altered behavior in a crustacean intermediate host: field and laboratory studies. J. Parasitol. 84: 1102-1106.

McCAHON C.P., MAUND S.J., POULTON M.J. 1991: The effect of the acanthocephalan parasite (Pomphorhynchus laevis) on the drift of its intermediate host (Gammarus pulex). Freshwater Biol. 25: 507-513.

MOORE J. 1983: Responses of an avian predator and its isopod prey to an acanthocephalan parasite. Ecology 64: 1000-1015.

MOORE J., GOTELLI N.J. 1990: Phylogenetic perspective on the evolution of altered host behaviours: a critical look at the manipulation hypothesis. In: C.J. Barnard and J.M. Behnke (Eds.), Parasitism and Host Behaviour. Taylor and Francis, London, UK, pp. 193-233.

POULIN R., CURTIS M.A., RAU M.E. 1992: Effects of Eubothrium salvelini (Cestoda) on the behaviour of Cyclops vernalis (Copepoda) and its susceptibility to fish predators. Parasitology 105: 265-271.

PULKKINEN K., PASTERNAK A.F., HASU T., VALTONEN E.T. 2000: Effect of Triaenophorus crassus (Cestoda) infection on behavior and susceptibility to predation of the first intermediate host Cyclops strenuus (Copepoda). J. Parasitol. 86: 664-670.

URDAL K., TIERNEY J.F., JAKOBSEN P.J. 1995: The tapeworm Schistocephalus solidus alters the activity and response, but not the predation susceptibility of infected copepods. J. Parasitol. 81: 330-333.

WEDEKIND C., MILINSKI M. 1996: Do three-spined sticklebacks avoid consuming copepods, the first intermediate host of Schistocephalus solidus? An experimental analysis of behavioural resistance. Parasitology 112: 371383.

WELLNITZ T.A., WARD J.V. 1998: Does light intensity modify the effect mayfly grazers have on periphyton? Freshwater Biol. 39: 135-149.

WILLIAMS D.D., MOORE K.A. 1985: The role of semiochemicals in benthic community relationships of the lotic amphipod Gammarus pseudolimnaeus: a laboratory analysis. Oikos 44: 280-286.

WOOSTER D.E. 1998: Amphipod (Gammarus minus) responses to predators and predator impact on amphipod density. Oecologia 115: 253-259. 